\title{
A Contrastive Analysis of the Imperfective Aspect in Chinese and English: Theoretical and Pedagogical Issues
}

\author{
I-hao Woo \\ The Citadel, The Military College of South Carolina, Charleston, U.S.A.
}

\begin{abstract}
This study addresses several theoretical issues and pedagogical implications of the imperfective morpheme -zhe in Mandarin Chinese and English present participle -ing. It first compares the similarities and differences between these two morphemes. The study then provides several teaching suggestions for a Chinese as Foreign/Second Language (CFL/CSL) class. The similarities between these two morphemes in Chinese and English not only show evidence of Universal Grammar (UG), but have important pedagogical implications.
\end{abstract}

Keywords: comparative linguistics, the progressive aspect, foreign language pedagogy

\section{Introduction}

Chinese imperfective -zhe and English present participle morpheme -ing show a great deal of similarities. For example, syntactically, these two morphemes both appear directly after the verb they modify as demonstrated in the two sentences in (1):

(1) a. Lisi chang-zhe ge ne.

Lisi sing-zhe song SFP.

"Lisi is singing".

b. John is singing now.

As showed, both Chinese -zhe in (1a) and English -ing in (1b) appear directly after the verb. Semantically, these two morphemes are similar in that they can be both used to signal a special type of imperfective aspect, the progressive aspect when they are used to modify an event denoting activity such as chang ge (sing song) (1a) or sing in (1b). They indicate that the event is ongoing at a specific time.

These two morphemes also have similar functions when they are used to modify verbs of posture/position as demonstrated in the two sentences in (2) below:

(2) a. Lisi zai sha fa shang zuo-zhe ne.

Lisi in sofa above sit-zhe SFP.

"Lisi is sitting in the sofa".

b. John is sitting in the sofa.

As can be seen, both -zhe in (2a) and -ing in (2b) appear after a verb of posture/position, namely to sit and they indicate continuation of the resultant state of the sitting event. In other words, they signal the continuous aspect. Finally, the two morphemes may also be used to modify a stative event such as hei (dark) in (3a) and

I-hao Woo, assistant professor, Ph.D., Department of Modern Languages, Literatures, and Cultures, The Citadel, The Military College of South Carolina. 
like in (3b):

(3) a. Zhei ge fang jian hei-zhe ne.

This CL room dark-zhe SFP.

"This room is pretty dark".

b. John is liking this play.

The similarity between these two morphemes in Chinese and English not only shows evidence of Universal Grammar (UG), but has important pedagogical implications for teaching Chinese as a Foreign/Second Language (CFL/CSL). The properties of the aspectual system shared by Chinese and English provide additional support for the existence of UG given that these two languages belong to two different languages families. This similarity suggests that a short comparison of the two morphemes in a CFL/CSL classroom may enhance language learners' acquisition of the usage of the imperfective -zhe. Therefore, in this paper, I give a detailed analysis of the properties of these two morphemes and present pedagogical suggestions for CFL/CSL classes.

The paper is organized as follows. In The Imperfection Aspect, I introduce the properties of the imperfective aspect placing the focus on the progressive aspect and the resultative imperfective aspect. In the next section, I discuss the aspectual properties of the morpheme -zhe and compare it with the English present participle morpheme -ing. I then provide suggestions for teaching the morpheme -zhe in a Chinese as a Foreign/Second Language class. Finally, I conclude this study.

\section{The Imperfective Aspect}

The imperfective aspect belongs to a type of viewpoint aspect, which has also been identified as grammatical aspect or outer aspect in the literature. According to Smith (1997), viewpoint aspect "functions like the lens of a camera, making objects visible to the receiver" (p. 61). It is mainly concerned with perfectivity of an event and it focuses all or part of a situation. Smith (1997) also claims that viewpoint aspect includes the perfective aspect, the imperfective aspect, and the neutral aspect.

Sentences with the imperfective aspect present part of the situation, providing no information about its initial and end points. According to Comrie (1976), while many languages express imperfectivity with one single category, there are other languages where imperfectivity is subdivided into a number of different categories. Comrie argues that the imperfective aspect can be further divided into two subgroups: the habitual aspect and the continuous aspect. He also argues that there are two types of continuous imperfective aspect: the progressive aspect and the non-progressive aspect. (4) below presents Comrie's (1976) classification oppositions:

(4) Comrie's (1976) classification of aspectual opposition is as follow:

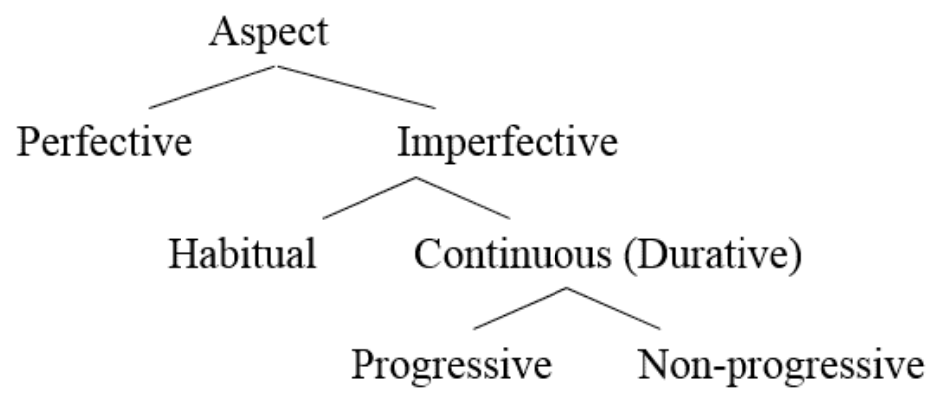


According to Comrie, these different sub-categories presented in (4) can be morphologically realized as different elements. Take the aspectual system in English for example. It uses the phrase used to to represent the habitual aspect, though only in the past tense (e.g., He used to work in Boston). The English progressive operator provides an example of imperfective viewpoint aspect. The main function of the progressive is to signal the ongoing process of an event at the reference time. It is neutrally available for dynamic situations such as Activity as (5a) and Accomplishment (5b), and it is generally not compatible with stative events such as $(5 \mathrm{c}):^{1}$

(5) a. John is running. (Activity)

b. John is writing a letter. (Accomplishment)

c. *John is knowing the person. (State)

The English progressive aspect can also be used with some Achievement verbs. Sentences like (6a) and (6b) containing an Achievement verb are instantaneous and have no internal stages. The progressive focuses on the preliminary stage of the event it interacts with and provides no information as to the outcome of the event.

(6) a. John is reaching the top of the mountain.

b. John is winning the Marathon.

With respect to the semantics and syntax of the progressive aspect, the theoretical framework assumed in this study is based on the one that has been developed by Klein (1994, 1995), Stowell $(1996,2007)$, Demirdache and Uribe-Etxebarria $(2000,2004,2007)$, and Arch $(2006,2014)$. In this framework, it is argued that temporal and aspectual interpretations are obtained by virtue of the relations that temporal intervals build up between one another. The relationships are established by the syntactic categories of tense and aspect, which are argued to be dynamic predicates that contain the same semantic primitives; however, these two predicates differ in that they order different temporal intervals. The set of time-denoting intervals that tense and aspect order consists of the following:

(7) a. The Reference Time (REF-Time): the speech time in a matrix clause.

b. The Assertion Time (AST-Time): the time for which an assertion is made.

c. The Event Time (EV-Time): the time at which the event/state denoted by the VP occurs or holds.

According to Demirdache and Uribe-Etxebarria (2004, 2007), tenses, aspects, and time adverbs express spatiotemporal relations (e.g., precedence, subsequence, or inclusion) between different time intervals. In general, there are three different temporal intervals: the Reference Time (REF-Time) is the speech time in a matrix clause as in (7a); the Assertion-Time is the time for which an assertion is made as in (7b); the Event-Time is the time at which the even/state denoted by the VP occurs or holds as in (7c). Following Klein $(1994,1995)$, they further argue that the ordering relation progressive aspect establishes is that the AST-Time is within the EV-Time as illustrated by the temporal schema in (8):

(8) Temporal Schema of the Progressive Aspect

AST-T

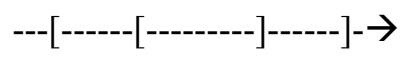

EV-T

\footnotetext{
1 The phenomenon does not mean that stative events cannot have a progressive reading. When the context allows, it is possible for a stative event to combine with the progressive aspect. The sentence in (i) gives an example:

(i) A: John just ate the whole steak in 2 minutes.

B: Oh, well. He was just being silly.
} 
As can be seen in (8), the progressive aspect indicates that the AST-Time is within the Event-Time. As for tense, it is argued that present tense indicates that the REF-Time is within the AST-Time as in (9a) and past tense indicates that the REF-Time is after the AST-Time as in (9b):

(9) a. Present Tense

REF-T

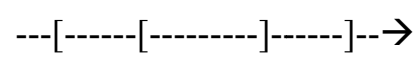

AST-T b. Past Tense

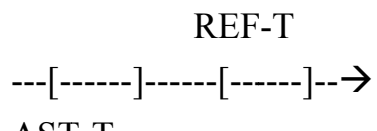

Extending Stowell's (1993) phrase structure for Tense, Demirdache and Uribe-Etxebarria $(2004,2007)$ further claim that syntactically, aspect is a spatiotemporal predicate which establishes an order relation between two time-denoting arguments and projects its temporal argument structural representations. According to these scholars, the null hypothesis is that tense and aspect are assigned isomorphic structural representation as demonstrated in (10):

(10)

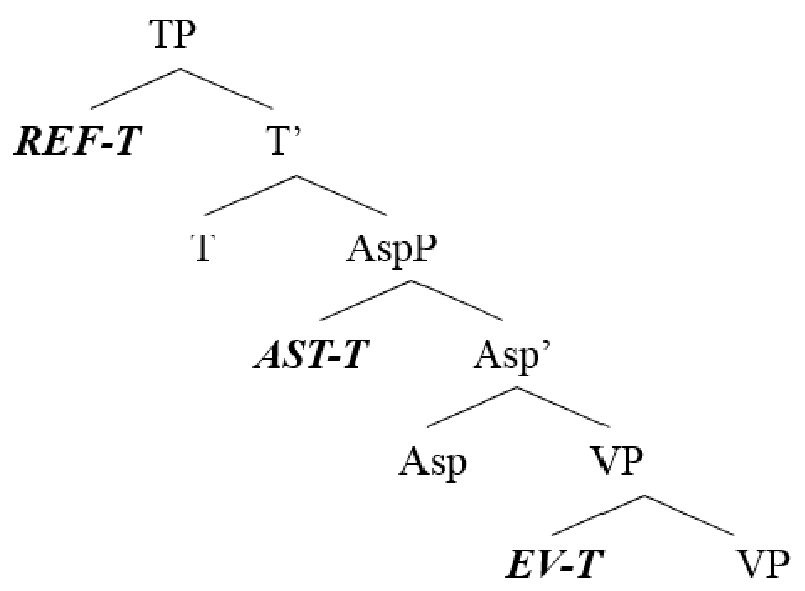

The structure in (10) syntactically breaks down tense and aspect into their respective semantic components. The functional heads Asp and $\mathrm{T}$ each relate two different temporal arguments. For example, Asp takes two arguments, the AST-Time as its external argument and the EV-Time as the internal one. What Asp does is ordering these two arguments. As represented in (8), progressive aspect indicates that the AST-Time contains the EV-Time. Therefore, progressive aspect indicates that its external argument (AST-Time) is within its internal argument (EV-Time). On the other hand, tense is a predicate that takes REF-Time as the external argument and AST-Time as the internal argument. Its function, then, is to order these two arguments. As represented in (9b), past tense indicates that the REF-Time is after the AST-Time; therefore, the temporal relation among the three different time intervals in a sentence like (11a) has the semantic schema in (11b) and the syntactic structure in $(11 \mathrm{c})$ :

(11) a. John was talking on the phone (when I enter the room).

b.

AST-T

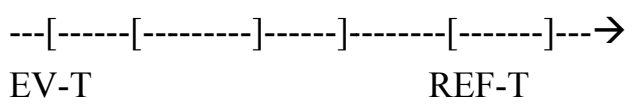


c.

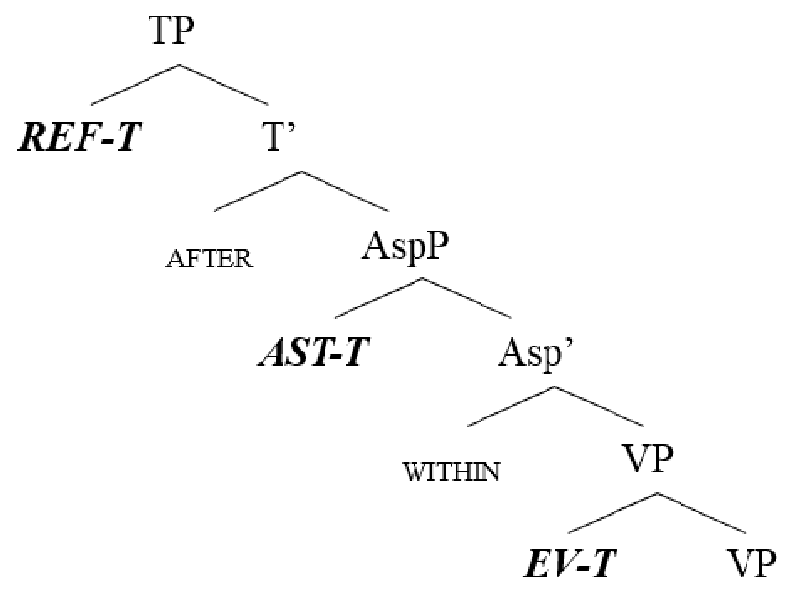

John talk on the phone

The temporal schema in (11b) is read as follows. The Reference Time (i.e., the time at which the sentence is produced) is after the Assertion Time, which itself is within the time at which John's walking is occurring. The syntactic structure is shown in (11c).

In addition to the progressive aspect, according to Smith (1997), there is another type of imperfective viewpoint: the resultative imperfective. Smith argues that "[r]esultative imperfective viewpoints present a state that follows the final point of a telic event. More precisely, such viewpoints focus on the interval after the change of state" (p. 76). Both Chinese and English have this type of imperfective viewpoint. For example, the English sentence in (12a) presents a state that follows the shirt-lying event. It is stative syntactically and semantically but it is morphologically identical to the progressive viewpoint aspect. According to Smith (12b) is a Chinese example with a resultative imperfective. The morpheme $-z h e$ is used to convey this aspectual information.

(12) a. John's shirts were lying on the sofa.

b. Men shang gua-zhe yi fu hua.

Door on hang-zhe one CL painting.

"There is a painting hanging on the wall".

\section{A Comparison of Chinese -zhe and English -ing}

In this section, I compare Chinese -zhe and the English present participle morpheme -ing. I first show how these two morphemes are used to modify an event denoting Activity in the sense of Vender (1967). I then discuss the properties of these two morphemes when they are used to modify a stative event. I also discuss the properties of the two morphemes when they are used to modify verbs of posture/position and wear-type verbs. Finally, I show some differences between these two morphemes.

\section{The Morphemes -zhe and -ing and Events Denoting Activity}

As presented, the morpheme -zhe can be used as a marker of the progressive aspect. This property is similar to that of the English present participle morpheme -ing. They can be both used to modify an event denoting Activity. I presented an example in sentence (1) and (13) provides an additional one: 
(13) a. Zhang san zuo-zhe zhong fan ne.

b. John is making lunch.

Zhang san make-zhe lunch SFP.

"Zhang san is making lunch".

As showed, both (13a, 13b) contain an event denoting Activity, namely, making lunch. According to Li and Thompson (1981), when the morpheme -zhe is used to modify an event denoting Activity along with the sentence final particle (SFP) $n e$, it indicates that the event is on-going at a certain point of time. In other words, it signals the progressive aspect. Like -zhe, the morpheme -ing in English has similar function when it is used to modify an event denoting Activity. The two languages, however, show some morphological differences. English contains the auxiliary verb $B e$, which signals the tense of the sentence. In contrast, Chinese does not contain an auxiliary verb (on the surface) but the sentence final particle ne is required.

In addition to sentences such as (13), there is another type of sentence that demonstrates the compatibility of -zhe with an event denoting Activity. The two sentences in (14) provide a demonstration:

(14) a. Ta qi-zhe ma zhao ma. (Smith, 1997)

He ride-zhe horse seek horse.

"He is looking for a horse while riding a horse (do something absent-mindedly)".

b. Ta chi-zhe fan kan bao. (Chan, 1980)

He eat-zhe rice read newspaper.

"He is reading the paper while eating".

According to Smith (1997), -zhe in (14a) appears in the subordinate clause, and its main function is to present a background effect. In this case, the aspectual marker -zhe is used in the subordinate clause and can be freely attached to the horseback riding event, an event denoting an Activity. Similarly, Chan (1980) argues that -zhe marks the simultaneity of an action, such as the eating event in (14b), with respect to the main event. The duration of the action must extend at least to include the time required to fulfill the main event. However, the sentences in (14) differ from the one in (13a) in that the SFP ne is not required.

Like the morpheme -zhe in Chinese, English present participle morpheme -ing can also be placed in a subordinate clause functioning as a manner modifier as well. The two sentences in (15) give a demonstration:

(15) a. John walked to school [while crying].

b. John rode a bike to school [while listening to the music].

As the two sentences in (15) show, English present participle morpheme -ing is like the morpheme -zhe, which also appears directly after the verb in the subordinate clause. The main function of the subordinate clause is to indicate the manner. This function is similar to that of Chinese -zhe although the conjunction word while is required in English.

\section{The Morphemes -zhe and -ing and Stative Events}

The two morphemes in Chinese and English can be used to modify stative events as well. Stative events include to know, to love, hei (black), hong (red), and many others. The sentences in (16) provide a demonstration in Chinese:

(16) a. Zhe ge fang jian hei-zhe ne.

This CL room black-zhe SFP.

"This room is pretty dark". 
b. Zhang san de lian hong-zhe ne.

Zhang san DE face red-zhe SFP.

"Zhang san's face is pretty red".

As showed, $(16 \mathrm{a}, 16 \mathrm{~b})$ both contain a stative event that is modified by the morpheme $-z h e$. However, according to studies such as Yeh (1993) and Smith (1997), -zhe is compatible only with stage-level states. Observe the two examples in (17):

(17) a. Lisi gao xing-zhe ne.

Lis happy-zhe SFP.

"Lisi is quite happy".

b. *Lisi zhi dao-zhe na ge da' an ne.

Lisi know-zhe that CL answer SFP.

"*Lisi is knowing that answer".

The marker $-z h e$ in (17a) co-occurs with the stage-level stative event gaoxing 'to be happy' but is incompatible with an individual-level state such as zhidao 'to know' in (17b). Yeh (1993) argues that stage-level states are more likely to change and they can therefore take -zhe. Similarly, Smith (1997) claims that the main function of $-z h e$ is to present a continuous and stable situation without regard to the initial or end point.

Li \& Thompson (1981) also indicate that -zhe can be used to modify a stative event. However, they claim that, $-z h e$ is used as an intensifier together with the sentence-final particle $n e$ in sentences such as (17a). Note that the SFP ne is needed when -zhe is used to modify a stative event, as shown in (17a); without the particle, the sentence sounds incomplete. Reaching a similar conclusion, He (1992) also argues that the function of -zhe is to intensify the degree of a stative event. Therefore, according to He (1992), the particle in (17a) has a meaning similar to the degree adverb hen (very).

Like Chinese, the English present participle morpheme -ing can be used to modify a stative event as demonstrated by the two sentences in (18) below:

(18) a. John is liking this play.

b. John is living in Boston.

According to Smith (1997), there are several specific connotations related to a stative event with the progressive aspect. For example, in a sentence such as (18a) the progressive aspect indicates the temporary duration of the liking event and that this event has an emotional color that is lacking in the neutral presentations of the stative event. Similarly, the living event in (18b) is temporary. Smith (1997) further indicates that when a stative event takes the progressive aspect, it is a type of marked aspectual choice.

Nevertheless, there are several stative verbs that cannot be modifying the morpheme -ing. The sentence in (19) gives an example:

(19) *John is knowing the answer.

As (19) shows, the stative verb know in English cannot be modified by English present participle -ing. It is similar to the Chinese sentence in (17b), which is also ungrammatical.

\section{The Morphemes -zhe and -ing and Verbs of Posture/Position and Wear-Type Verbs}

In addition to an atelic event (i.e., an Activity or a State), the morpheme -zhe can also be used to modify verbs signaling a resultant state that is associated with their activity meanings. In this study, for the sake of 
simplicity, I will refer to them as "wear-type verbs". Other verbs that have similar properties are dai "to wear", na "to hold", gua "to hang" and many others. In addition to wear-type verbs, verbs of posture/position can be modified by the morpheme -zhe as well (Li \& Thompson, 1981). The sentences in (20) and (21) give two examples:

(20) a. Lisi na-zhe yi ben shu.

Lisi hold-zhe one CL book

"Lisi is holding a book".

b. Lisi shou li na-zhe yi ben shu.

Lisi hand inside hold-zhe one CL book.

"Lisi is holding a book in his hand".

(21) a. Lisi zai sha fa shang zuo-zhe.

Lisi on sofa above sit-zhe.

"Lisi is sitting on the sofa".

b. Lisi zai chuang shang tang-zhe.

Lisi on bed above lie-zhe.

"Lisi is lying in the bed".

According to Smith (1997), -zhe in sentences such as (20) and (21) indicates continuation of a state that is as the result of an action. She further claims that an event such as the book-holding event in (20a) is an Accomplishment and argues that when the morpheme -zhe is combined with an Accomplishment, it signals continuation of the resultant state. However, Lin (2002) argues against such a proposal. To explain the grammaticality of (20a), Lin claims that the sentence can be rephrased as (20b), which contains a locative inversion construction. According to Lin, locative inversion is stative, and therefore, -zhe may appear in a sentence such as (20b). In addition, the aspectual marker -zhe is compatible with verbs of posture/position as shown by (21). In this case, -zhe signals the ongoing posture or physical dispositions of an entity at a location. The morpheme -zhe in both types of verbs discussed here has the same function: It expresses continuation of a state that is related to an action. For instance, the state of holding a book in (20a) is related to the action of picking up the same book.

Similarly, when the English present participle morpheme -ing is combined with a verb of posture/position as in (22a) or a wear-type verb such as (22c), it indicates the continuation of the action:

(22) a. John is sitting in the sofa. (verb of posture/position)

b. John is sitting down in the sofa.

c. John is wearing a hat. (wear-type verb)

d. John is putting on a hat.

The sentence in (22a) suggests that when the morpheme -ing in English is combined with a posture/position verb such as sit, it cannot have a progressive reading. The sentence cannot mean that John is in the progress of sitting down; nevertheless, when the particle down is added as in (22b), the sentence is grammatical, and can have a progressive meaning. The sentence in (22c), which contains a wear-type verb, does not have a progressive reading as well. It indicates continuation of the hat being on John's head. However, as (22d) demonstrates, a different verb put on has a progressive reading when it is modified by the morpheme -ing. 


\section{Language Variations}

Although the two morphemes in Chinese and English show a great deal of similarities, there exist several differences. For example, the imperfective -zhe has been argued to be incompatible with a telic event such as an Achievement. For instance, according to Xiao and McEnery's (2004) corpus study, none of the sentences with the morpheme -zhe contains an Achievement, as demonstrated by the sentences in (23):

(23) a. *Lisi kan-wan-zhe zhe pian xiao shuo. (Xiao \& McEnery, 2004)

Lisi read-finish-zhe this CL novel.

"Lisi is finishing reading the novel".

b. *Lisi si-zhe.

Lisi die-zhe.

"Lisi is dying".

The sentences in (23) both contain an event denoting an Achievement; nevertheless, they are ungrammatical. In addition, according to Lin (2002), -zhe is not compatible with the other type of telic event: an event denoting an Accomplishment. This statement can be demonstrated by (24) below:

(24) *Lisigai-zheyi dongfangzi. (Lin, 2002)

Lisi build-zhe one CL house

"Lisi is building a house".

As shown, the sentence in (24) cannot have the meaning that the house-building event is in progress at the reference time; it is simply ungrammatical.

The sentences in (23) and (24) suggest that $-z h e$ is incompatible with telic events. This is different from English -ing, which can be used to modify events denoting both Achievement and Accomplishment. The phenomenon demonstrates that the two morphemes in Chinese and English are not completely identical. There exist language variations.

\section{Pedagogical Implications}

As I demonstrated in the previous section, the morphemes -zhe and -ing are similar in many ways; therefore, a short comparison of these two morphemes will familiarize CFL/CSL learners with the usages of the morpheme. In this section, I provide some teaching suggestions that will facilitate CFL/CSL learners' learning process.

\section{The Progressive Usage of -zhe and -ing}

Table 1 summarizes the usage of Chinese -zhe and English -ing when they are used to modify an event denoting Activity:

Table 1

The Progressive Usage of Chinese -zhe and English -ing

\begin{tabular}{|c|c|c|}
\hline Chinese & English & Usages \\
\hline $\begin{array}{l}\text { a. Lisi ting-zhe yin yue ne. } \\
\text { Lisi listen-zhe music SFP. }\end{array}$ & b. Lisi is listening to the music. & An action is in progress at a certain point of time. \\
\hline $\begin{array}{l}\text { c. Lisi chang-zhe ge qi zi xing che. } \\
\text { Lisi sing-zhe song ride bicycle. }\end{array}$ & d. Lisi is riding a bike while singing. & Manner modifier \\
\hline
\end{tabular}

In a CFL/CSL classroom in which English is used as the main medium of instruction, a comparison of these two morphemes is suggested given that they share similar properties. First, the morphemes -zhe and -ing 
both appear immediately after the verb they modify. Secondly, these two morphemes signal the progressive aspect when modifying verbs denoting Activity. Table 1 gives an example which can be used in the classroom demonstrating the similarities. The sentence in (a) and (c) in the Table 1 are two examples in which -zhe is used to modify an Activity and (b) and (d) are their English translations, respectively. As demonstrated, the functions of these two morphemes are identical when they are used to modify an Activity. However, the use of the sentence final particle $n e$ is needed in a sentence such as (a). This fact must be addressed and practiced in the classroom. In (c), the verb to which the morpheme -zhe is attached functions as a manner modifier; in this case, the sentence final particle $n e$ is not needed.

\section{The Durative Usage of -zhe and -ing}

Table 2 provides a summary of the usage of the morphemes -zhe and -ing when they are used to modify a wear-type verb and a verb of posture/position. As discussed in the previous section, both morphemes do not signal the progressive aspect but the durative aspect. They both indicate continuation of a state as a resulted of an action:

Table 2

The Durative Usage of Chinese -zhe and English -ing

\begin{tabular}{lll}
\hline Chinese & English & Usages \\
\hline $\begin{array}{l}\text { a.Lisi dai-zhe yi ding hong mao zi. } \\
\text { c. Lisi zai sha fa shang zuo-zhe. }\end{array}$ & b. Lisi is wearing a red hat. & Continuation of a state \\
Lisi in sofa above sit-zhe. & d. Lisi is sitting in the sofa. & Continuation of a state \\
\hline
\end{tabular}

As demonstrated by the table, the main usage of the morpheme -zhe is to signal continuation of a state when it is used to modify a wear-type verb and a verb of posture/position. The sentences in (a) and (c) give two examples and sentences (b) and (d) are their English translations, respectively. As can be seen, both morphemes appear directly after the verbs that they modify and they signal continuation of a resultant state. A short comparison of -zhe and -ing, therefore will facilitate CFL/CSL learners' acquisition of the usage of the morpheme $-z h e$.

\section{The Intensifying Usage of -zhe in a Sentence with a Stative Event}

Recall that both -zhe and -ing can be used to modify stative events. Table 3 provides a summary of the usage of the morphemes -zhe and -ing when they are used to modify a stative event:

Table 3

The Intensifying Usage of -zhe

\begin{tabular}{|c|c|}
\hline Example & Usage \\
\hline $\begin{array}{l}\text { a. Zhe ge fang jian hei-zhe ne. } \\
\text { This CL room black-zhe SFP. } \\
\text { "This room is pretty dark". }\end{array}$ & Intensifying; temporary \\
\hline b. John is liking this play. & Vivid; temporary \\
\hline
\end{tabular}

Given that the usages of -zhe and -ing are not completely identical, I use a two by two table instead of a three by three one here. As demonstrated in Table 3, the usage of -zhe in a sentence such as (a) is to signal the intensifying reading of the stative event. However, like the sentence (b) in English, the sentence in (a) also has a temporary flavor. The darkness of the room is temporary. This property should be addressed while we present the usage of -zhe. Also, the sentence final particle $n e$ is needed when -zhe is used to modify a stative event such 
as hei (black) in (a). This fact must be addressed in the classroom as well.

\section{Conclusion}

In this paper, I have compared Chinese durative -zhe and English present participle -ing. I showed that in many cases, the functions of these two morphemes are identical although the two language show morphological variations. The similarities between these two morphemes in Chinese and English not only show evidence of Universal Grammar but have important pedagogical implications for teaching Chinese as a Foreign/Second Language.

I have also provided several teaching suggestions for a CFL/CSL class. However, it is important that we keep in mind that grammar instruction in a foreign or second language class should be precise and brief. All the grammatical patterns must be used and practiced in real-life situations. The instruction of grammar is not the center of language teaching but simply provides foreign and second language learners with a learning tool facilitating their learning process.

\section{References}

Arch, M. (2006). Individuals in time: Tense, aspect, and the individual/stage distinction. Amsterdam: John Benjamins.

Arch, M. (2014). The construction of viewpoint aspect: the imperfective revisited. Natural Language \& Linguistic Theory, 32 , 791-831.

Chan, M. (1980). Temporal reference in Mandarin Chinese: An analytical-semantic approach to the study of the morphemes le, zai , zhe, and ne. Journal of Chinese Language Teachers Association, 15(3), 33-79.

Comrie, B. (1976). Aspect: An introduction to the study of verbal aspect and related problems. Cambridge: Cambridge University Press.

Demirdache, H., \& Uribe-Etxebarria, M. (2000). The primitives of temporal relations. In R. Martin, D. Michaels, and J. Uriagereka (Eds.), Step by step: Essays on minimalist syntax in honor of Howard Lasnik (pp. 157-186). Cambridge: MIT Press.

Demirdache, H., \& Uribe-Etxebarria, M. (2004). The syntax of time adverbs. In J. Guéron and J. Lecarme (Eds.), The syntax of time (pp. 143-180). Cambridge, MA: The MIT Press.

Demirdache, H., \& Uribe-Etxebarria, M. (2007). The syntax of time arguments. Lingua, 117, 330-366.

He, B. (1992). Situation types and aspectual classes of verbs in Mandarin Chinese (Doctoral dissertation, The Ohio State University).

Klein, W. (1994). Time in language. New York: Routledge.

Klein, W. (1995). A time relational analysis of Russian aspect. Language, 71(4), 669-692.

Li, C., \& Thompson, S. (1981). Mandarin Chinese: A functional reference grammar. Berkeley and Los Angeles, CA: University of California Press.

Lin, J. W. (2002). Aspectual selection and temporal reference of zhe in Mandarin Chinese. Tsinghua Journal of Chinese Studies, 32(2), 257-296.

Lü, S. (1980). Eight hundred words of modern Chinese. Beijing: The Commercial Press.

Smith, C. (1997). The parameter of aspect. The Netherlands: Kluwer Academic Publisher, Dordrecht.

Stowell, T. (1996). The phrase-structure of tense. In J. Roorych and L. Zaring (Eds.), Phrase structure and the lexicon (studies in natural language and linguistic theory) (pp. 277-291). Dordrecht: Kluwer.

Stowell, T. (2007). The syntactic expression of tense. Lingua, 117, 437-463.

Vendler, Z. (1967). Linguistics in philosophy. Ithaca, NY: Cornell University Press.

Xiao, R., \& McEnery, T. (2004). Aspect in Mandarin Chinese: A corpus-based study. The Netherlands: John Benjamins, Amsterdam.

Yeh, M., (1993). The stative situation and the imperfective zhe in Mandarin. Journal of Chinese Language Teachers Association, 28(1), 69-98. 